\title{
Intersubjectivity in the Imagination and Feelings of the Infant: Implications for Education in the Early Years
}

\author{
Colwyn Trevarthen and Jonathan Delafield-Butt
}

\begin{abstract}
This chapter presents the child as a creature born with the spirit of an inquisitive and creative human being, seeking understanding of what to do with body and mind in a world of invented possibilities. He or she is intuitively sociable, seeking affectionate relations with companions who are willing to share the pleasure and adventure of doing and knowing with 'human sense'. Recent research traces signs of the child's impulses and feelings from before birth, and follows their efforts to master experience through stages of self-creating in enjoyable and hopeful companionship. Sensitive timing of rhythms in action and playful invention show age-related advances of creative vitality as the body and brain grow. Much of shared meaning is understood and played with before a child can benefit from school instruction in a prescribed curriculum of the proper ways to use elaborate symbolic conventions. We begin with the theory of James Mark Baldwin, who observed that infants and young children are instinctive experimenters, repeating experience by imitating their own as well as other's actions, accommodating to the resources of the shared world and assimilating new experiences as learned ideas for action. We argue that the child's contribution to cultural learning is a good guide for practice in early education and care of children in their families and communities and in artificially planned and technically structured modern worlds of bewildering diversity
\end{abstract}

\footnotetext{
"In the last 50 years, theory about how the mind of the child grows with the body and develops intelligence has changed. Psychobiological research has revealed that infants move with rhythms of prospective awareness from birth, show insight for learning what the world affords, and share their feelings of imaginative vitality in affectionate adventures with other persons." (Trevarthen and Bjørkvold, 2016)
}

In this chapter, with different experiences in the exploration of the movements of infants (Trevarthen, 1979, 1992, 2001; Delafield-Butt and Gangopadhyay, 2013), we use detailed evidence from recordings of how happy infants communicate to develop the idea that a child learns by being full of hopeful emotion and the will to live with loved parents and lively brothers and sisters (Delafield-Butt and Trevarthen, 2013; Trevarthen and Delafield-Butt, 2013). The behaviour of a young human being is not just for attracting protection and care, and not only cognitive or rational for learning about objective facts. It is adapted to come to life in, intimate and playful companionship, or 'intersubjective awareness'. Experienced teachers know, as loving parents do, that human life begins with an eagerness to share meaning in the pleasure of activity with friends. 
Leaders of modern child psychology have seen that young children learn, not passively, but by active, intentional engagement of their bodies to see hear and touch objects that catch their interest. With James Mark Baldwin (1895), Jean Piaget (1953) and Lev Vygotsky (Vygotsky, 1978), we accept that knowledge is gained by moving with curiosity. New evidence shows that even newborn infants move to share their interest in objects and events with persons they know well in an intimate sympathy of actions. Their innocent bodies and minds require both selfsustaining, regulation of inner vitality for well-being, and imaginative control of movement by perception of the outside world for the successful completion of tasks, and they enjoy showing and sharing of intentions with other persons. From the beginning, conscious interaction with the world is a living process, not only a collection and retention of facts to be learned, but a story of experience to be created, and it seeks companionship in the pleasure of discovery. Knowledge is gained through 'participatory sense-making', with social others (De Jaeger and Di Paolo, 2007; Trevarthen and Delafield-Butt, 2013; Reddy, 2008, 2015). A search for understanding of this vital inter-mental learning is leading infant pedagogy today to a reappreciation of the child's contribution to transmission of knowledge and skills (Trevarthen, Gratier and Osborne, 2014; Trevarthen and Delafield-Butt, 2015).

Of course, a newborn infant has limited powers of action and mobility. A one-year-old cannot walk or talk, and they know little about the outside world. But this physical weakness and inexperience, which needs for a long period of parental care, does not prevent the baby from attending intelligently to people and what they are doing. The baby moves to join in actions of a helper who is picking up and carrying them (Fantasia et al., 2016), or one who is offering objects with admiration for the baby's actions, and for the mind that guides them. In a few weeks the baby is starting to use vocal sounds as signs for marking special experiences in a 'line mode' of consciousness that can be about non-present things or happenings 'someplace, sometime' (Donaldson, 1992, p. 50). A lively mind is eager to share remembered meanings with others in imagination for moving. Narratives or stories are being created to represent projects of 'serially ordered actions' that become a 'common sense' world (Bruner, 1990, 2003; Donaldson, 1992; Trevarthen and Delafield-Butt, 2013; Delafield-Butt and Trevarthen, 2015).

Thinking about actions through time is what Karl Lashley (1951) identified as the foundation for the grammar of language before Chomsky (1965) presented his cognitive theory of a separate instinct for grammar. Lashley added the remarkable suggestion that, "analysis of the nervous mechanisms underlying order in the more primitive acts may contribute ultimately to the solution even of the physiology of logic" (p. 121). Our special human abilities for accumulating complex skills for inventing institutions, making buildings and machines, celebrating the arts and recording and thinking about our culture in language, have their origins in what a young baby can do in the rhythm of playful movements with someone they love (Delafield-Butt and Trevarthen, 2015).

A nine-month old is combining gestures and vocalizations in non-verbal messages of a 'protolanguage', which parents easily understand to mean ideas like "Isn't that interesting", "I want that one", "What a terrible noise", "Go away from me". (Halliday, 1975). Acts of 'languaging' are made well before the child can 'talk properly' (Bruner, 1977; Donaldson, 1978; Maturana, Mpodozis and Letelier, 1995). We explore these 'acts of meaning', presenting our research and that of others to illustrate the richness of play of infants with their mothers, fathers or other intimate companions. And we consider their significance for the development of self-confident knowledge and skills of both children and teachers in Early Childhood Education and Care (ECEC) settings today.

\section{Story-Telling from Birth: Making Sense of Experience In Non-Verbal Narrative}

As we have been taught by the founder of a rich educational psychology, Jerome Bruner, who died in June 2016 at the age of 100, we are born 'story-telling creatures' (Bruner, 2003). All 
our narratives, whatever they are 'about', are motor performances with serial organization through episodes of vitality (Stern, 2010). We explore space and time in active experience, and build social understanding by sharing feelings and intentions in movement (Delafield-Butt and Trevarthen, 2015). Narrative behaviour, "inherent in the praxis of social interaction [even] before it achieves linguistic expression" (Bruner, 1990, p. 77) is a foundation of conversational meaning-making and culture (Read and Miller, 1995; Cobley, 2014). In our stories we make sense of our experiences, evaluate our actions and understand our intentions with aesthetic and moral feelings about how they are performed (Kearney, 2002; Cunliffe and Coupland, 2012).

The creation of sequences of expressive behaviour - with the phases of 'introduction', 'development', 'climax' and 'resolution' enjoyed in the proto-conversations, action games and baby songs with infants - represent the 'communicative musicality' of relationships (Gratier and Trevarthen, 2008; Gratier and Apter-Danon, 2009; Malloch and Trevarthen, 2009). As psychiatrist Daniel Stern taught us, ideas are expressed as 'proto-narrative envelopes' and 'schemas of being-with' in communication between a mother and infant (Stern 1995), and with universal human 'vitality dynamics' (Stern, 2010). The emotions of these simple human stories inspire reflections with an artful sense of beauty (Delafield-Butt and Trevarthen, 2013; Trevarthen and Malloch, 2016).

Study of the initiatives of infants for learning in playful ways has important implications for a responsive pedagogy that aims to guide a child to a productive and self-confident adult life in family and community. New evidence from research on animal emotions for social cooperation confirms that a human life follows a creative imaginative path based on feelings shared as emotional intelligence or 'affective consciousness'. which directs collaborative action to make a new and valued reality for the 'cognitive consciousness' of a community (Panksepp and Biven, 2012). In concert with sociocultural theories (Vygotsky, 1978, Rogoff, 2003) we consider that such advances cannot be comprehended without consideration of their location within particular cultural practices and values (Negayama et al., 2015). The foundation for our knowledge is in our innate feelings for collaborative awareness in the experience of action (Delafield-Butt and Trevarthen, 2015).

\section{Philosophy of Meaning: A Phenomenological Approach to a Brain Science of Infant Intersubjectivity and Its Motor Intelligence}

The power of the brain to integrate its activities prospectively in coherent rhythmic patterns of moving is recognised in the philosophy of phenomenology, which admits that it is movements of the body that create and respond to consciousness by acting with the brain-generated 'subjective' time of intentional doing and thinking (Merleau-Ponty, 1962; Goodrich, 2010).

The pioneer of modern self-sensing neuroscience and discoverer of the Integrative Action of the Nervous System, Charles Sherrington, said, when summarizing his scientific philosophy at the age of 80, that the development of any individual person cannot be an act of 'memory', since each life is a new phenomenon - it must be considered an act of 'imagination' (Sherrington, 1955, Chapter 4, "The Wisdom of the Body", pp. 103-104). Indeed, all animal movement must anticipate consequences that affect continuation of life, which requires an imagined awareness of the environment to be encountered, including other intentional beings.

This awareness of life in action becomes appraised and evaluated from the beginning of life, giving rise to Jaak Panksepp's 'affective intelligence' generated by core brainstem systems (Panksepp, 2005; Porges and Furman, 2011). We now recognize that basic perceptual and affective experience is generated, not by habits learned in the cerebral cortices, but by the impulses of the brainstem, forming a primary conscious intelligence from which abstract and reflective intelligence in later childhood and adulthood develops (Northoff and Panksepp, 2008; Panksepp and Northoff, 2009). Feelings in communities of animal beings shape the evolution and development of acquired knowledge and skills (Packard and Delafield-Butt, 2014). 
The core, primary Self of a human infant moves to explore the world and learns the contingencies of action, but it is limited in scope and power (Delafield-Butt and Gangopadhyay, 2013). Human consciousness of shared meaning develops in sophistication and power as the cortex matures, in a childhood of affective, embodied experiences in sympathetic company (Vandekerckhove and Panksepp, 2011). Simple actions performed in utero and the first gestures in early life, tested in communication with a caring and sensitive caregiver, are brought together, or 'chained', to compose habits or projects of action that may reach far into the future (Pezzulo and Castelfranchi, 2009).

We have to grasp the idea of a fundamental 'motor intelligence' for acting with awareness if we are to understand how consciousness develops with increasing efficiency. In the 1920s a young Russian neurophysiologist, Nikolai Bernstein (1967), used frame-by-frame examination of film taken at 40 frames per second to trace the regulation of forces in the moving body of a tooluser, a runner, or a child learning to walk. He proved that the vast array of motor components involved in any body action are assembled in advance by a motor image formed in the brain. The intended movement so conceived is highly efficient, wasting almost no energy. Furthermore, well-done movements are always rhythmic, smoothing out the irregular inertial forces they master through planned steps of time. David Lee (2005) has employed accurate mathematical analysis of how movements of an animal are guided precisely to reach a goal, and shown that there has evolved a special formulation for this control, which he calls a 'tau' function. It is common to a wide range of animal brains, and appears to be a biological universal (Delafield-Butt and Schögler, 2007; Delafield-Butt et al., 2012). Even the sucking movements of a newborn baby obey this basic principle of prospective control (Craig and Lee, 1999). Moving rhythmically in time also enables synchronization between individual actors in a dance of life that composes meaningful projects of cooperation.

There have been advances in applying such thinking about the time of movements in the mind to explain the inter-subjectivity of communication (Thelin, 2014). In The Laws of Emotion, Frijda (2007) reviews what is known about the importance of the timing of emotional expressions, and of regulating their intensity and duration in immediate intimate encounters between persons. The topic of Vitality Dynamics, richly explored by psychiatrist Daniel Stern (2010), explains how a life time of 'affective' states of the self is made apparent in 'affecting' signals to others, with subtle regulations of 'arousal' in the vigor of actions. This is how affective signals communicate experience in 'the present moment' of life together (Stern 2004).

Like Goodrich, Stern (2010) perceives the advantages of a phenomenology which, he says:

provides an account of the subjective world experienced as it is lived, pretheoretically, pre-reflectively. The subjective, phenomenal world is as whatever is passing across the "mental stage", right now. It does not concern itself with how the scene got on the mental stage, nor why it got there, nor when, nor whether it is "real" in any objective sense. This current of philosophy ... provides a starting place to look for vitality dynamics or the feel of being alive. William James (1890), Edmond Husserl (1964), and Merleau-Ponty (1962) are the most influential thinkers for this present work. (p. 34)

Sharing the same inborn sense of time, we develop conventional doing and thinking, or meaning-making (Trevarthen, 2015). 


\section{Genesis of Conventional Meaning Learned In Shared Experience}

\section{Communication of Interests and Feelings in Proto-Conversational Narratives at Two Months: Educating Motherese}

Early in the 1970s researchers working independently in Boston and New York to trace the development of motor activities aimed at objects and people reported evidence that the infants had elaborate motives for sharing interests, purposes and feelings.

An anthropologist and linguist Mary Catherine Bateson, who had studied universal gestural principles of human communication described by Ray Birdwhistle (1970), worked with Margaret Bullowa to understand the early acquisition of speech production and perception in the Speech and Communication Group at the Massachusetts Institute of Technology (Bullowa, 1979). Bateson, while expecting the birth of her daughter, made a detailed description of films of an infant 7 to 14 weeks of age in spontaneous interactions with the mother, as follows:

"... the mother and infant were collaborating in a pattern of more or less alternating, nonoverlapping vocalization, the mother speaking brief sentences and the infant responding with coos and murmurs, together producing a brief joint performance similar to conversation, which I called 'proto conversation'. ... These interactions were characterized by a sort of delighted, ritualized courtesy and more or less sustained attention and mutual gaze. Many of the vocalizations were of types not described in the acoustic literature on infancy, since they were very brief and faint, and yet were crucial parts of the jointly sustained performances." (Bateson, 1979, p. 65, emphasis added).

Bateson was convinced that the infant was participating in mutual consciousness with a subtle grammar of movements to communicate, neither of which requires the symbolic conventions of language.

In New York, Daniel Stern, also inspired by Birdwhistell's 'kinesics', found that three-and-ahalf-month-old twins were actively guiding their mother in playful exchanges by precise engagement of expressive movements (Stern, 1971). This work led Stern away from conventional ideas of child psychiatry and psychoanalysis to path-finding studies of The Interpersonal World of the Infant (Stern, 2000), and to elucidation of the dynamic principles of Forms of Vitality in body movement (Stern, 2010).

In 1968 Jerome Bruner, who had introduced in preceding decades a philosophy of education that recognized the initiative of the child for learning, and the importance of 'value and need' for perceiving meaning, reported on a transformation of the work of the Center for Cognitive Studies at Harvard to focus on infant intelligence and learning, with inspiration from ethological work on non-human primates. He set up, with the support of the pediatrician T. Berry Brazelton, a richly equipped research facility for use of a variety of recording devices and high-speed film to observe motor patterns and selective attention in young infants. Discoveries were made by visiting researchers and doctoral students, including Hanuš Papoušek and Tom Bower, that brought to light very early awareness of objects in body-related space and well-timed and directed actions to make sensory contact with them (Bruner, 1968).

With Brazelton's advice and Martin Richards, a zoologist interested in maternal behaviour of mammals, a private film studio was set up to record natural spontaneous communication between infant two- to three-months-olds and their mothers, and to observe actions that the infants directed to objects (Bruner, 1968). Using a single camera, the behaviours of the infant were observed from directly in front, and the mother's behaviours were recorded from a large front-surface mirror placed beside the infant (Trevarthen, 1974, 1975, 1977, 1979). Two important findings were clearly established.

First, the behaviours that infants addressed to objects and those they aimed at their mother's attention were different. We called them 'doing' with things, and 'communicating' with a 
person. Secondly, in the communications that were supported by the mother's affectionate interest the babies took the initiative. For most of their 'conversations' the mothers were imitating the infant's expressions of vitality and their emotions of pleasure, displeasure, interest or disinterest. Rarely did the infant imitate the mother. (Figure 2.1)
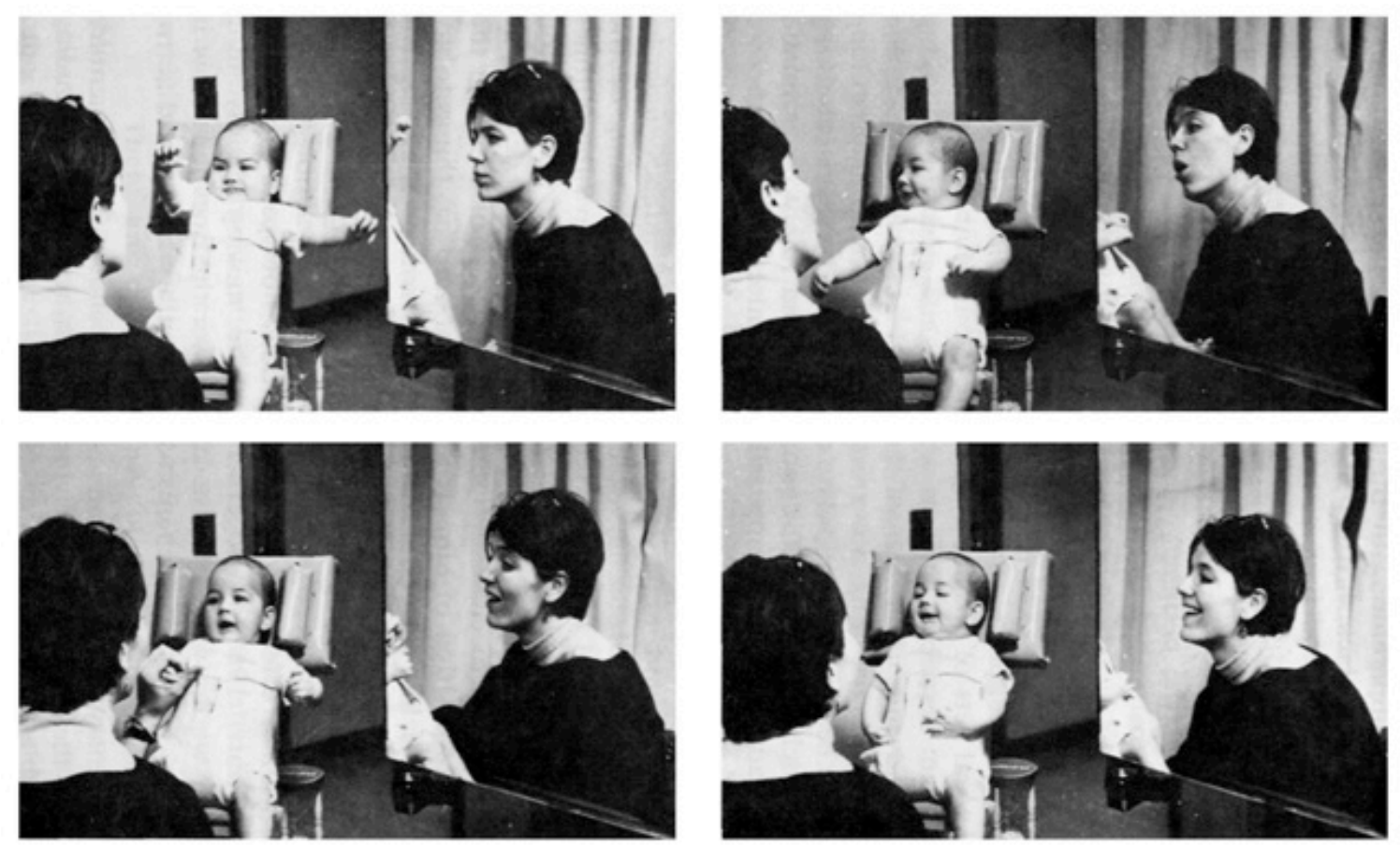

Figure 2.1:

"Photographic samples show how a mother may adopt postures and expressions to closely mirror what her baby does. The intense mutuality or harmony of the behaviour comes initially from the infant responding to the mother's friendly behaviour in kind. Then the development is principally due to the mother accepting the expressions of the infant as models for her expression, or, rather, as indicative of an emotion which she may both share with her infant and express in like manner." (Trevarthen, 1977, p. 241).

From a film made at the Center for Cognitive Studies, Harvard, in 1968. The infant is three months old. These pictures were first published in Trevarthen, 1974

None of the three above studies used psychological testing according to an experimental protocol. All relied on detailed recordings that were studied later to measure their rhythms and intentional or affective forms.

In his summary of the work at Harvard, Bruner emphasized that,

"As the joint efforts within the Center have turned more toward infancy, there has occurred a gradual change toward the viewpoint of a naturalist exploring a new species, and away from an exclusive emphasis on the testing of specific hypotheses derived from a general theory of infant development. The objective of the research is much as it has been in the past: to elucidate the processes by which human beings achieve, retain, transform and communicate information."

(Bruner, 1968, p. ii).

In that study and in further work with infants of the same age in Edinburgh, both the subjective self-regulations of the infant, and the inter-subjective patterns that sustained the 'dialogues of movement' were recorded in photographs and drawings traced from films. They supported the 
theory that the young infant has strong abilities for sharing a primary intersubjective awareness with an attentive adult, and special actions of hand gesture, facial expression and 'prespeech' movements of tongue and lips were demonstrated (Trevarthen, 1974, 1977, 1979). In her work Bateson (1971) used refined acoustic analysis of illustrative examples of vocal engagement to represent this dialogic motivation.

\section{Exchanges in Dialogues of Imitation With Newborns}

After the revelations from film studies of communication with infants after the second month, proving their conversational abilities, detailed analysis of voluntary engagements of babies from the first hours after birth confirmed the innate foundations of the mutual awareness. Until then, the firmly held belief of doctors, psychologists and educators was that a newborn cannot imitate expressive movements. This was the view of Sigmund Freud and Jean Piaget. Disproof of this theory was anticipated by Henri Wallon in the 1940s, then clearly demonstrated by Olga Maratos in 1973 when she reported the findings of her PhD research to Piaget at the University of Geneva. Piaget conceded 'indeed they imitate', but kept reservations about what it signified for their state of awareness. Despite intense controversy, with ardent defense of the learning theory, clear evidence accumulated that alert infants were ready immediately after birth to imitate a wide range of movements of another person's head, eyes, mouth, vocal sounds and hand gestures (Nagy, 2011; Kugiumutzakis and Trevarthen, 2015).

An important additional discovery was that the imitating infants wanted to participate in a reciprocal exchange, in a confirmation of mutual awareness. Emese Nagy changed the interpretation that the imitations were an automatic 'mirroring' by showing that a newborn could repeat an imitated act as a 'provocation' to invite a reciprocal imitation by the adult. The baby was accepting the expressive movement as an invitation to a creative dialogue of signs, or the affirmation of a convention of communication as an 'act of meaning' (Nagy and Molnár, 2004; Nagy, 2008).

Kugiumutzakis, in 1983, had recorded how an infant girl, filmed with him at 20 minutes after her birth, participated in a cooperative exchange of mouth opening movements, shifting attention from his mouth when attending to his gesture, to his eyes when watching for his response. (Figure 2.2). 

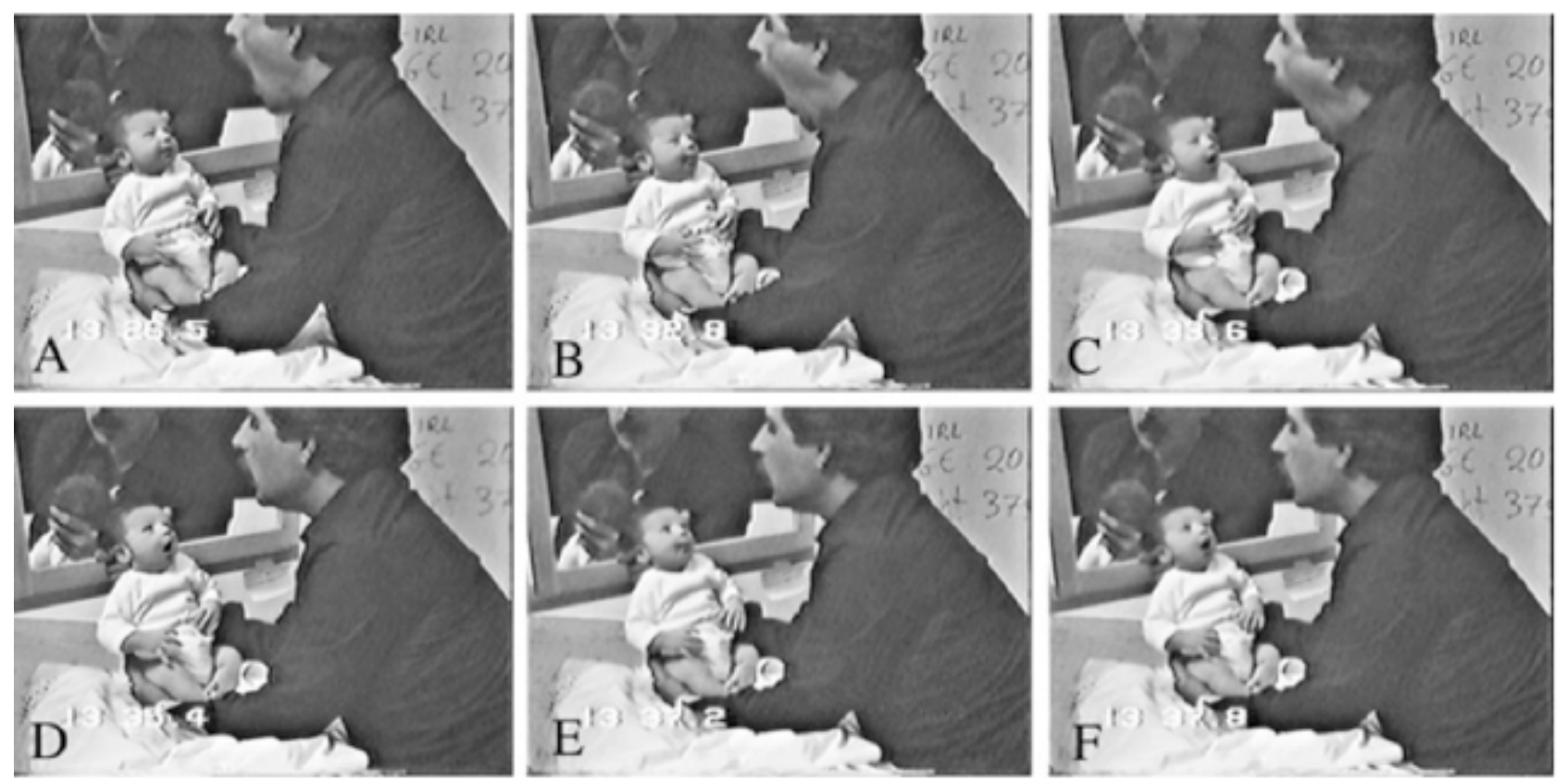

Figure 2.2:

A cycle of imitations of Mouth Opening with a female infant 20 minutes after birth. Recorded a maternity hospital in Herakleion, Crete in 1983 by Giannis Kugiumutzakis for his $\mathrm{PhD}$ research at the University of Uppsala.

A 0 sec. GK presents a wide open mouth for the first time to the attentive infant, I, who is focusing on his mouth, and with slightly closed eyes and pursed mouth.

B $6.3 \mathrm{sec}$. GK opens his mouth for the fourth time. I continues to observe his mouth with evident interest. The right hand moves up.

C $7.1 \mathrm{sec}$ GK opens his mouth for the fifth time. I imitates him once, synchronously while watching his mouth. The right hand closes.

D 8.9 sec. I imitates a second time, looking up at the researcher's eyes as he waits.

E $10.7 \mathrm{sec}$. Both pause, waiting. The infant is still looking at his eyes.

F 11.3 sec. I makes a third large imitation while looking at the researcher's mouth, looking for a response.

$\mathrm{GK}=$ Giannis Kugiumutzakis. $\mathrm{I}=\mathrm{Infant}$

Nagy (2011) recorded a more rapid exchange of finger movements with a newborn infant which similarly demonstrates the two phases of the infant's interest, observing the proffered expressive movement, an index finger extension and imitating, then watching for and accepting a return imitation. (Figure 2.3). 

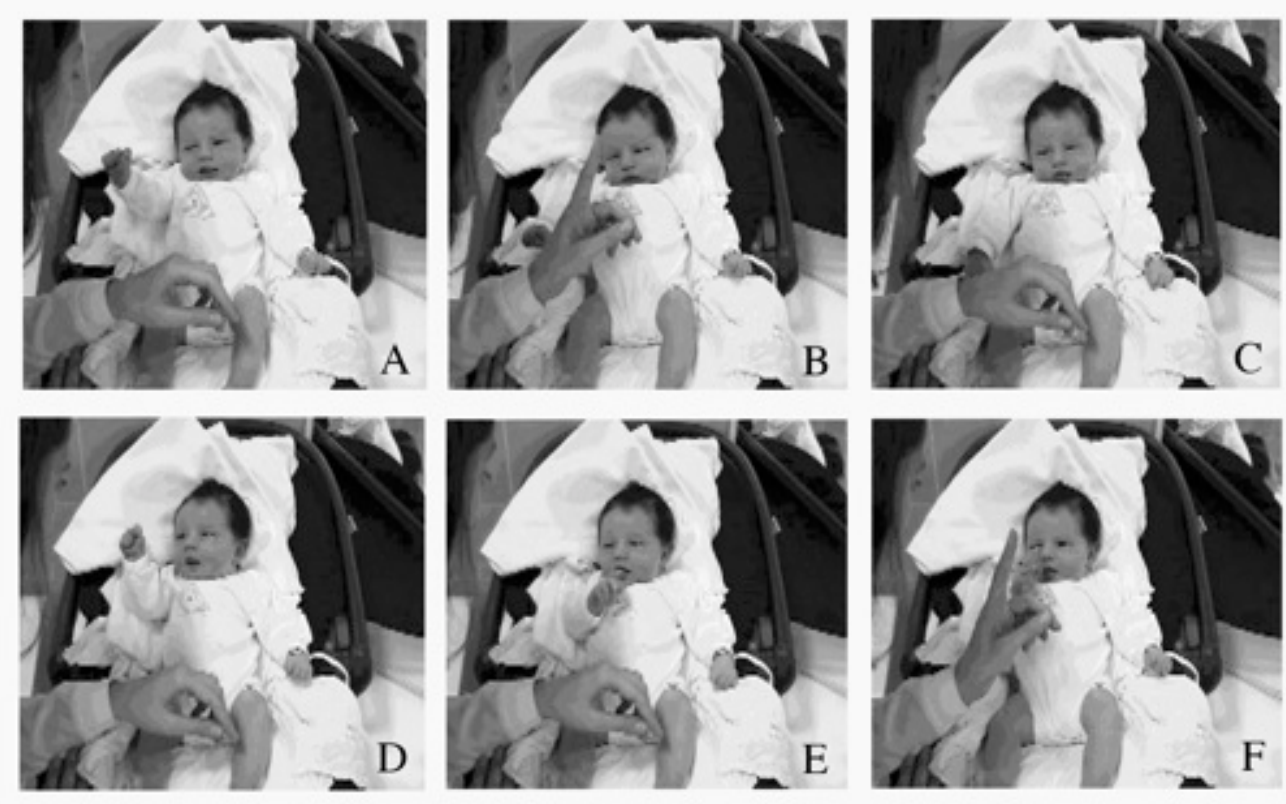

Figure 2.3:

A short exchange of intentions with interest recorded by Emese Nagy, of a sign she offered to the infant by extending the index finger of one hand, which the infant first imitates, then seeks an imitative response from the adult elicited by what Nagy described as an act of 'provocation'.

A 0 sec. The infant is watching her own hand move

B 2 sec. Emese Nagy holds up her left hand with index finger extended. The infant looks at the hand.

C 4 sec. Emese's hand is lowered, and the infant waits, looking at it.

D $10 \mathrm{sec}$. After a long pause the infant suddenly raises her right hand and watches as she makes an extension of the index finger.

E $12 \mathrm{sec}$. The infant looks back to Emese with her hand up and the finger extended, mouth open, as if questioning.

F $15 \mathrm{sec}$. Emese responds with an index finger extension, and the infant watches intently with an 'attentive' mouth 
Development of Narrative Rituals In Play, and Playful Sharing of Objects in Unexpected Ways.

After the discovery of proto-conversational exchanges of the early months, in which the infant took a leading role, study of how individual baby-mother pairs changed their behaviour through the first year brought to light 'age-related changes' in the infants' interests and actions, which led the mother to adopt different strategies to share interests, feelings and actions (Trevarthen, $1988,1992,2001)$. Infants develop their abilities through measures of time with new powers of movement with awareness.

A rich record of these motivated changes, which are found to be similar in babies who are growing up in all kinds of family and culture, is presented with hundreds of beautifully presented photographs in Lynne Murray's book The Psychology of Babies (Murray, 2014). We have related the key changes to developments in the human brain that regulate both movements and perception, and changes in feelings and their emotional expression (Trevarthen and Aitken, 2003). In the second edition of The Interpersonal World of the Infant (Stern, 2000) Daniel

Stern presents a lucid overview of how innate motivations of infants are retained as a foundation for the later stages.

With advances in their visual awareness after 3 months, and as support of the head, tracking movements of the eyes and control of arm and hand extensions develop, babies become more curious about their surroundings. They make efforts to examine nearby objects and look out to more distant places. In response, their mothers become more playfully seductive, to draw their attention. This generates what we called the Period of Games, first by exchanging expressions of curiosity and joy with teasing, or Person-Person games, then after 6 months Person-PersonObject games with 'toys' as the infants become more determined to explore anything they might get their hands on, enjoying the sights and sounds of actions with attractive things (Trevarthen, 1977; Trevarthen and Hubley, 1978).

Vasudevi Reddy has given attention to the use of 'joking, teasing and mucking about' to bring joy to these engagements of play, and she has charted the parallel development of selfconsciousness or awareness of the Self in the appreciation of an Other (Reddy, 2003, 2005, 2008; Reddy and Trevarthen, 2004). This may be described as a maturation of two kinds of feeling for experiences, an 'aesthetic' appreciation of what may be done by engagement with 'things', and a 'moral' engagement with the feelings of a 'person' as partner in communication (Trevarthen and Reddy, 2016).

The changes in the infants' motives and their communication with affectionate company reflect transformations of the 'vitality dynamics' elucidated by Daniel Stern (Stern, 2010), who demonstrates that each phase in the development of increasingly elaborate expressions of "how to move' acts as a foundation that persists through the later attainments.

These transformations of the young human being, affecting their exploration of the material world and their relationships with companions and hence their learning of meaning for life in a particular family and community are an essential part of human nature, adapted, from infancy, for education in the ways of a community with its culture (Trevarthen and Delafield-Butt, 2013, 2015).

\section{Sympathetic Rhythms of Communicative Musicality In Proto-Conversations, Action Games and Nursery Songs}

From the beginning, the new descriptive research of the natural spontaneous actions of infants has drawn researchers' attention to the timing, especially the infant's creation and coordination of rhythms in all kinds of movement -- looking with head and eyes, reaching out to point to or grasp objects, making vocalisations and gestures that express feelings, and their sensitivity for the rhythms of other persons' actions and especially the vocal sounds they make in speech or 
song. This discovery has been supported by research on the prospective control of all animal movements, including the unique human powers of bipedal locomotion, the manipulation of objects as tools or toys, and the elaboration of narratives by creative patterns of voice and gesture (Bernstein, 1967; Lee, 2005).

Scientific research on the rhythms of life and their sharing in early childhood has benefitted greatly from the use of musical acoustics (Malloch, 1999) to reveal fine details of motor expression and their regulation by an Intrinsic Motive Pulse (IMP). "Musicality in human motives, the psycho-biological source of music, is described as a talent inherent in the unique way human beings move, and hence experience their world, their bodies and one another." (Trevarthen, 1999, p. 155).

With Stephen Malloch, we have studied the rhythms of action games with infants and baby songs in many different cultures and found universal principles of timing, expression and narrative form (Malloch, 1999; Malloch and Trevarthen, 2009). The infants are not compliant imitators in these celebrations of joy in relationships with familiar people, they are active and stimulating performers. One amazing film shows how a 5-month-old baby born totally blind conducts with her left hand her Swedish mother's singing of a baby song that is known all over Scandanivia. The baby moves with the delicate gestures of a professional conductor, and anticipates important moments in the drama by a fraction of a second, moving just before her mother's note changes. She describes the melody with the feelings of her body (Trevarthen, 1999, p. 185).

Dancing celebrations and songs are attractive to infants as their bodies gain strength in the middle of the first year and key components like the pulse and rhyming vowels are learned and repeated. They are becoming ways of sharing rituals of unspoken common sense, leading to the special traditional ways of a particular culture (Bråten and Trevarthen, 2007). The baby is beginning to make sounds that have the recognisable 'accent' of speech in their family. This is the time when they show they have a disposition to master a language.

\section{Secondary Intersubjectivity Leading to Speech}

Language is 'about' actions, events, and desirable or interesting objects in a shared world, which by use of symbolic representation, does not have to be present. Speech is the key that opens the door to a great expansion of the world which becomes known with good companions, first in remembered times and places, then in an ideal world of meanings anywhere or anytime (Donaldson, 1992, on 'modes of mind'). Studies of communication before proto-language have discovered an important step in the infant's awareness of other person's purposes and interests at 9 months, a transformation in the initiative of the child for learning, one which changes the way adults behave as teacher-companions.

Penelope Hubley documented development of one infant girl through her first year by comparing film showing how she shared the fun of games with her mother's expressions of intentions and feelings, for example in the sharing of rhythms and melodies in action games and baby songs like "Rock-a-bye baby", "Round and round the garden" and "Clappa-clappahandies". Hubley found that the infant's interest in sharing of objects as toys in play also changed, and that this affected the way the mother communicated with her:

In the development of fundamental human skills, a regulated pattern of change is clear in the first year of life. A large step towards confidence in "self" and confiding in others is expressed at about 9 months. It is significant that the word confidence means both skill in making acts as an independent self, and a sense of being in a trusting relationship to another self. (Trevarthen and Hubley, 1978, p. 226). 
Within a couple of weeks, an infant gained a more serious interest in doing things together with her mother, taking particular interest in a companion's ideas about what to do with a selected object or to combine objects in a particular way, and to communicate 'about' them. We called the new kind of sociability 'secondary intersubjectivity' or 'cooperative awareness' (Trevarthen and Hubley, 1978; Hubley and Trevarthen, 1979), wishing to relate it to - but also differentiate it from - the primary direct person-to-person engagement that motivates the 'primary intersubjectivity' of proto-conversation with a two-month-old (Bateson, 1979; Trevarthen, 1979). Piaget, in his study of the development of an individual's 'thinking' (Piaget, 1962) identified this change at 9 months as the beginning of the infant's 'concept of the object'. He allows the infant no special awareness of persons who share intentions and feelings and may cooperate in the generation of meaning, which has been given special importance by researchers attentive to the development of language.

Elizabeth Bates (1979) found 9 months to be the age when a child brings awareness of a person nearby into the consciousness of what the immediate world affords. Both the object of interest and the person who is present are alive in the imagination, and intentional communication about it begins, for example turning to ask for help to reach a wanted object, or looking back to the other to see if they are following an arm that is pointing to an attractive object or event. Scaife and Bruner (1975) had observed a change in readiness to follow another's direction of regard around 9 months. Tomasello (2008) identifies seeking for 'joint attention' as The Origin of Human Communication. Again, it needs to be recognized that this change is not just a cognitive or practical appreciation of a context for action. The key change is a combining of attentions to objects with sympathy for the vocal and gestural expressions of companions (Reddy et al., 1997). The invitation to join comes from a new kind of social curiosity in the child (Esteve-Gibert, et al., 2016).

A very important indication of the child's investment of purpose in a shared task, like the special form of delight shown in participation of a 6-month-old in a favourite game, is the expression of shared satisfaction or 'pride' that is addressed to others for their admiration. This leads us to recognize that for a young child it is especially important and rewarding to share knowledge and skills with moral feelings of personal joy or distress (Trevarthen, 2005).

Figure 2.4: A one-year-old shows her talents.

A. In the recording room, Basilie enjoys the comedy when her mother pretends to be sad.

B., C. and D. Mastering a task. She takes the wooden figure offered by her mother, with a request "Put the doll in the truck". Basilie carefully puts it in the truck (C): then (D) looks with a self-satisfied expression at her mother who says, "What a clever girl!"

E At home Basilie and her mother read. Basilie is studying her book, the mother is intently occupied with a document, perhaps a telephone bill.

F Basilie drops her book and points to the mother's paper, with a critical vocal comment, 'jargon' without words, but with intense prosody communicating criticism. This appears to be a response to the concerned expression of her mother.

\section{Infants and Toddlers as Personalities: Pride and Shame in Presentation of an Imaginative Self to Others.}

Draghi-Lorenz, Reddy and Costall (2001) insist on 're-thinking the development of 'non-basic' emotions', rejecting the theory that infants come with only a set of mindless reflex emotional responses to stimuli that cause bodily pleasure and pain, with social signaling of automatic 
reactions of distress or anger. Reddy (2008) has elaborated the richer approach demonstrating the developmental importance of complex 'moral' feelings of self-conscious shyness, pride and shame, which are sensitive to appreciation of the attentions and feelings of others (Figure 2.4, D). These are the 'relational affects' identified by Stern (2000), regulating emotions of spiritual awareness that communicate the values of relationships (Hay, 2006). Emotions of the spirit are powerful in early childhood (Hay and Nye, 2006), and they are critically involved in the process of engagement in education from infancy (Trevarthen, 2005). Children learn with pride, and shame restricts understanding and learning.

Our personality and our personal history depend on the recognition by others, including our parents and our teachers. Their attitude towards us is something we depend on as a source of affection and self-confidence. As Bruner says, in his celebration of our 'story-telling' imagination, our narrative of life gives us our identity, and helps us learn.

Why are we so intellectually dismissive towards narrative? ... Storytelling performs the dual cultural functions of making the strange familiar and ourselves private and distinctive. If pupils are encouraged to think about the different outcomes that could have resulted from a set of circumstances, they are demonstrating usability of knowledge about a subject. Rather than just retaining knowledge and facts, they ... use their imaginations to think about other outcomes. ... This helps them to think about facing the future, and it stimulates the teacher too. (Bruner, 1996, pp. 39-40).

\title{
Reforming Educational Practice for Early Years With the Evidence from Infancy
}

\begin{abstract}
"The roots of all sciences and arts in every instance arise as early as in the tender age, and that on these foundations it is neither impossible nor difficult for the whole superstructure to be laid; provided always that we act reasonably as with a reasonable creature."
\end{abstract}

(John Amos Komensky (1592-1671), known as Comenius, in The School of Infancy. Quoted by Quick, 1910, pp. 144-145).

Understanding that infants can communicate their intentions and feelings and want to share experiences confirms what experienced teachers of early years and affectionate parents know, that convivial play is the generator of learning from birth. Before a child is ready to accept formal instruction in language, literacy and numeracy they need to enjoy a free life in a safe and interesting environment shared with affectionate companions.

This, of course, is not a new discovery. Comenius, the Moravian philosopher, pedagogue and theologian who wrote The School of the Mother's Breast (1628), School by Play (1630) and The Gate of Languages Unlocked (1631), and who is known as a creator of schools and as a teacher who elucidated the best principles for educating children from birth to the age of six, appreciated the infant's playful creativity and its contribution to human learning. In the $19^{\text {th }}$ Century Robert Herbert Quick (1910) described "a growing science of education" intended to help teachers welcome the initiatives of all children to share discoveries in imaginative ways. He recorded the insights of the Jesuits of the $16^{\text {th }}$ Century, who criticized the restriction of teaching to book learning and said young children must exercise their bodies, and Rabelais who ridiculed the absurd idea of 'pouring in' formulated knowledge. Following them, Pestalozzi and Froebel worked as teachers to reduce the misfortunes of young children obliged to work too soon at prescribed tasks, instead promoting their freedom to enjoy sociable learning at play in nature. 
At the end of the $19^{\text {th }}$ Century James Mark Baldwin proposed that all life actively tests its awareness with 'circular reactions' in which an initiative for action repeats itself to test stimulation, retaining the vitally good and pleasurable relations with the environment and suppressing bad and unpleasant stimulation. He inspired Piaget's theory of active learning and Vygotsky's explanation of the social development of thought and language with the child as playful agent, and he opened the way to understanding how 'self-imitation' leads to reciprocal imitation with others as the key motive of communication (Nadel, 2014). But Baldwin's understanding was rejected by the reductive psychology of behaviourism, and it gained recognition in his time only in the writings of philosophers, including Bergson, James, and Dewey.

In the 1920s Alfred North Whitehead, argued for appreciation of the first 'romantic' stage of the educational experience, and retention of its creative energy through to study at the University. He observed that in school childish imagination is transformed into the stage of 'precision' which concerns 'exactness of formulation'. In resistance to this limitation, Whitehead helped Susan Langer develop a philosophy of art in movement, presented as Philosophy in a New Key (Langer, 1942).

Jean Piaget $(1951,1962)$ described the infant mind as 'egocentric'. He failed to notice that attractive expressions by eyes, face, voice and hands show more than "pleasure in mastery" of a practical task, and did not appreciate that 'circular reactions' are, as Baldwin showed, readily shared with teachers, if they are not too preoccupied with reason and unreceptive to playful invention.

Jerome Bruner, who already in the 1940s insisted on the importance of a child's purposes and feelings for learning, expanded his philosophy of education in a new way by leading work in the Center for Cognitive Studies at Harvard to study the convivial enjoyment of intentions and problem solving by infants (Bruner, 1968). Margaret Donaldson $(1963,1978)$, also showed that three and four-year-old children appreciate other persons' points of view to experience a world shared purposefully and with emotional evaluation. They enjoy playing with differences of belief, as long as they do not receive imperative correction.

The foundations of education, in every culture, are in the development from birth of human motives to test and expand active experience, and to share it with companions, 'story-telling' for fun (Bruner, 1996; Trevarthen, Gratier and Osborne, 2014), with emotions of 'human sense' (Donaldson, 1978). To understand how we can best support the growth of this curiosity and sociability in infants and toddlers, we can learn from researchers in the arts, especially music. This is the belief of Loris Malaguzzi of Reggio Emilia in Italy, who insists on giving the "hundred languages" of childhood in play with all sorts of media the freedom to discover how they may be used in skills of everyday life. "The program is based on the principles of respect, responsibility, and community through exploration and discovery in a supportive and enriching environment based on the interests of the children through a self-guided curriculum." (http://en.wikipedia.org/wiki/ReggioEmiliaapproach). That is how childish enthusiasm motivates the learning of conventional practices and beliefs to supporting the traditions and inventions of a culture (Rogoff, 2003).

The views of Pestalozzi and Froebel inspired in turn the views and practices of Maria Montessori (1897-1952) and Jerome Bruner (b. 1915, and still teaching), which follow Comenius in their efforts to reduce misfortunes of young children and promote their enjoyment of learning (Trevarthen and Bjørkvold, 2016).

These different approaches have led to an acceptance by developmental psychology of the rich imaginative consciousness or 'spirit for life in movement' of a newborn, and appreciation of their special human abilities for communicating 'consciousness' as intentions to know with feelings of curiosity and enjoyment, both defined differently from verbal thoughts or rational explanations that may be developed later to describe 'cognition' of a material causal world. 
There have been great pioneers of this sense of being a human being with a human mind that lacks words and cognitions abstracted from active motor use. Their advice must guide educators in modern Western cultures.

\title{
Modern Prescriptions for Accepting Natural Impulses for Learning
}

\begin{abstract}
Early childhood is "...a period of momentous significance for all people growing up in [our] culture... By the time this period is over, children will have formed conceptions of themselves as social beings, as thinkers, and as language users, and they will have reached certain important decisions about their own abilities and their own worth."

(Donaldson, Grieve and Pratt, 1983, p. 1. Quoted to introduce New Zealand's early childhood curriculum Te Whariki, 1996)
\end{abstract}

This quotation from Donaldson, Grieve and Pratt (1983) supports the understanding of the role of childhood in transmission of culture that has guided the New Zealand formulation of Te Whäriki an inspiring bicultural ECEC curriculum that is inclusive of under three-year-olds (Te Whāriki, 1996)

Indigenous views concerning the natural talents of the very young child (Nuttall, 2013; White and Mika, 2013) demonstrate respect for what Margaret Donaldson (1978) calls 'human sense', common to all cultures, and her recognition that the normal development to a meaningful life for a self-consciousness personality needs oral and practical transmission of culture-specific 'common sense' in intersubjective encounters. Donaldson insists that a balance is required between acceptance of the natural eagerness of the child to learn in companionship, and the need for guidance in disciplined methods of learning by instruction from teachers in a planned education (Donaldson, 1992, pp. 245-266).

In Scotland, we are fortunate to have these principles adopted into the Curriculum for Excellence (Education Scotland, 2009) as principles of education that celebrate the child's agency and well-being made in intersubjective engagement with teachers and professional caregivers as a priority for professional practice. This commitment is evidenced in childcentred pedagogies that attend to the affective nature of the child to work with his or her intentions in creative, imaginative projects that can be achieved, developing confidence in a secure and responsible companionship. The non-verbal nature of intersubjective relations, building narratives of meaning with patterned autonomic arousal and shared affect become cornerstones of a sensitive pedagogy that can capture the imagination and interest of children, even those with so-called behavioural difficulties, to help them to discover and find interest in learning (Delafield-Butt and Adie, 2015; 2016). Such pedagogies, seek to support every child's interests and capacities to nurture and bring out the best in that child, and have sensitivity for whatever social or emotional difficulties they may have (Gunn and Delafield-Butt, 2016).

Every child's learning is by nature affective and purposeful, never just cognitive - and it is adapted to come to life in intimate and playful companionship. This is a fundamental principle for an effective educational pedagogy, and is no less true for the education of infants, who are beginning to be inquisitive about arbitrary knowledge and skills. 


\section{References:}

Baldwin, J. M. (1895). Mental Development in the Child and the Race: Methods and Processes. New York: Macmillan

Bates, E. (1979). The Emergence of Symbols: Cognition and Communication in Infancy. NY: Academic Press.

Bateson, M.C. (1979) The epigenesis of conversational interaction: A personal account of research development, in M. Bullowa (ed.), Before Speech: The Beginning of Human Communication.. London: Cambridge University Press. pp.63-77

Bateson, M. C. (1971). The interpersonal context of infant vocalization. Quarterly Progress Report of the Research Laboratory of Electronics, 100, 170-176. Boston: Massachusetts Institute of Technology.

Bernstein, N. (1967) Coordination and Regulation of Movements. New York: Pergamon.

Birdwhistell, R. (1970). Kinesics and Context. Philadelphia :University of Pennsylvania Press.

Bråten, S.. and Trevarthen, C. (2007). Prologue: From infant intersubjectivity and participant movements to simulations and conversations in cultural common sense. In S. Bråten (Ed.) On Being Moved: From Mirror Neurons to Empathy, pp. 21-34.

Amsterdam/Philadelphia: John Benjamins

Bruner, J. S. (1968). Processes of Cognitive Growth: Infancy. (Heinz Werner Lectures, 1968) Worcester, Mass: Clark University Press with Barri Publishers.

Bruner, J. S. (1977). Early social interaction and language acquisition. In H. R. Schaffer (Ed.), Studies in Mother-Infant Interaction: The Loch Lomond Symposium. London: Academic Press, 271-290.

Bruner, J. S. (1990). Acts of Meaning. Cambridge, Mass.: Harvard University Press.

Bruner, J. S. (1996). The Culture of Education. Cambridge, MA.: Harvard University Press.

Bullowa, M. (1979). Introduction. Prelinguistic communication: A field for scientific research. In M. Bullowa, ed. Before Speech: The Beginning of Human Communication, 1-62. London, Cambridge University Press.

Chomsky N. (1965) Aspects of the Theory of Syntax. Cambridge, MA: MIT Press.

Cobley, P. (2014). Narrative (2nd ed.). New York: Routledge.

Craig, C. M., and Lee, D. N. (1999). Neonatal control of nutritive sucking pressure: Evidence for an intrinsic tau-guide. Experimental Brain Research, 124(3), 371-382.

Cunliffe, A., and Coupland, C. (2012). From hero to villain to hero: Making experiences sensible through embodied narrative sensemaking. Human Relations, 65(1), 63-88.

De Jaegher, H., and Di Paolo, E. (2007). Participatory sense-making. Phenomenology and the Cognitive Sciences, 6, 485-507.

Delafield-Butt, J. T., and Gangopadhyay, N. (2013). Sensorimotor intentionality: The origins of intentionality in prospective agent action. Developmental Review, 33(4), 399-425.

Delafield-Butt, J., and Adie, J. (2015). Learning Embodied Narrative Patterns of MeaningMaking: Nurturing human nature in school. . University of Crete Annual Psychology Journal (2014 Annual Edition).

Delafield-Butt, J., and Adie, J. (2016). Embodied Narrative Meaning-Making: Nurturing human nature in school. Mind Brain and Education, in press.

Delafield-Butt, J. T., Pepping, G.-J., McCaig, C. D., and Lee, D. N. (2012). Prospective guidance in a free-swimming cell. Biological Cybernetics, 106, 283-293. 
Delafield-Butt, J. T., and Schögler, B. (2007). The ubiquitous nature of tau. In P. G.-J. and M. Grealy (Eds.), Closing the Gap. Hillsdale, NJ: Erlbaum.

Delafield-Butt, J. T., \& Trevarthen, C. (2013). Theories of the development of human communication. In P. Cobley \& P. Schultz (Eds.), Theories and Models of Communication (pp. 199-222). Berlin/Boston: De Gruyter Mouton.

Delafield-Butt, J. T and Trevarthen, C. (2015). The ontogenesis of narrative: From movements to meaning. Frontiers of Psychology, 6:1157 doi: 10.3389/fpsyg.2015.01157

Donaldson, M. (1978). Children's Minds. Glasgow: Fontana/Collins.

Donaldson, M. (1992). Human Minds: An Exploration. London: Allen Lane/Penguin Books.

Donaldson, M., Grieve, R., and Pratt, C. (Eds.) (1983). Early Childhood Development and Education: Readings in Psychology. Oxford: Basil Blackwell.

Draghi-Lorenz, R., Reddy, V. and Costall, A. (2001). Re-thinking the development of 'nonbasic' emotions: A critical review of existing theories. Developmental Review, 21(3), 263-304.

Education Scotland (2009). Curriculum for Excellence. http://www.educationscotland.gov.uk/learningandteaching/earlylearningandchildcare/curr iculum/supportingearlylevel/index.asp

Esteve-Gilbert, N., Prieto, P. and Liszkowski, U. (2016). Twelve-month-olds understand social intentions based on prosody and gesture shape. Infancy, 1-22. DOI: 10.1111/infa.12146

Fantasia, V., Markova, G., Fasulo, A., Costall, A. and Reddy, V. (2016). Not just being lifted: infants are sensitive to delay during a pick-up routine. Frontiers in Psychology, 6:2065. doi: 10.3389/fpsyg.2015.02065

Frijda, N. H. (2007) The Laws of Emotion. Mahwah NJ: Erlbaum

Goodrich, B.G. (2010). We do, therefore we think: time, motility, and consciousness. Reviews in the Neurosciences, 21(5), 331-61

Gratier, M. and Trevarthen, C. (2008) Musical narrative and motives for culture in motherinfant vocal interaction. The Journal of Consciousness Studies, 15(10-11): 122-158.

Gratier, M., and Apter-Danon, G. (2009). The musicality of belonging: Repitition and variation in mother-infant vocal interaction. In Malloch, S., and Trevarthen, C. (eds.), Communicative Musicality. Oxford: Oxford University Press, 301-327

Gunn, K. C. M., and Delafield-Butt, J. T. (2016). Teaching Children With Autism Spectrum Disorder With Restricted Interests: A Review of Evidence for Best Practice. Review of Educational Research, 86(2), 408-430.

Halliday, M. A. K. (1975). Learning How to Mean: Explorations in the Development of Language. London: Edward Arnold

Hay, D. (2006). Something There: the Biology of the Human Spirit. London: Darton Longman and Todd

Hay, D. and Nye, R. (2006). The Spirit of the Child. London: Jessica Kingsley Publishers.

Hubley, P. and Trevarthen, C. (1979). Sharing a task in infancy. In Uzgiris, I. (ed.) Social Interaction During Infancy: New Directions for Child Development, 4 (57-80). San Francisco: Jossey-Bass.

Husserl, E. (1964). The Phenomenology of Internal Time Consciousness. (J. S. Churchill, trans.). Bloomington IN: Indiana University Press.

James, W. (1890). The Principles of Psychology, Volumes I and II. New York: Henry Holt and Co. 
Kearney, R. (2002). On Stories. London: Routledge.

Kugiumutzakis, G. and Trevarthen, C. (2015). Neonatal Imitation. In: James D. Wright (editorin-chief), International Encyclopedia of the Social and Behavioral Sciences, 2nd edition, Vol 16. Oxford: Elsevier. pp. 481-488. ISBN: 9780080970868.

Lashley, K. S. (1951). The problems of serial order in behavior. In: L. A. Jeffress (ed.), Cerebral Mechanisms in Behavior, pp. 112-136. New York: Wiley.

Lee, D. N. (2005). Tau in action in development. In J. J. Rieser, J. J. Lockman and C. A. Nelson, eds. Action As an Organizer of Learning and Development, pp 3-49. Hillsdale, NJ: Erlbaum.

Malloch, S. (1999) Mother and infants and communicative musicality. In Deliege, I. (ed ). Rhythms, Musical Narrative, and the Origins of Human Communication. Musicae Scienticie, Special Issue, 1999-2000 (29-57), Liege, Belgium: European Society for the Cognitive Sciences of Music.

Malloch, S., and Trevarthen, C. (2009). Musicality: Communicating the vitality and interests of life. In Malloch, S., and Trevarthen, C. (eds.), Communicative Musicality: Exploring the basis of human companionship. Oxford: Oxford University Press, 1-12.

Maturana, H., Mpodozis, J. and Letelier, J. C. (1995). Brain, language and the origin of human mental functions. Biological Research 28(1): 15-26.

Merleau-Ponty, M. (1962). Phenomenology of Perception (Smith C, trans). London: Routledge and Kegan Paul. (Original in French, 1945).

Murray, L. (2014). The Psychology of Babies. London: Constable and Robinson.

Nadel, J. (2014) How Imitation boosts Development In young infants and in children with Autism Spectrum Disorders by Oxford: Oxford University Press.

Nagy, E. (2008). Innate Intersubjectivity: Newborns' Sensitivity to Communication Disturbance. Developmental Psychology, 44(6), 1779-1784.

Nagy, E. (2011). The newborn infant: A missing stage in developmental psychology. Infant and Child Development, 20: 3-19.

Nagy, E. and Molnár, P. (2004). Homo imitans or Homo provocans? The phenomenon of neonatal initiation. Infant Behavior and Development, 27, 57-63.

Negayama, K., Delafield-Butt, J. T., Momose, K., Ishijima, K., Kawahara, N., Lux, E., et al. (2015). Embodied Intersubjective Engagement in Mother-infant Tactile Communication: A cross-cultural study of Japanese and Scottish mother-infant behaviours during infant pick-up. Frontiers in Psychology, 6.

Northoff, G., \& Panksepp, J. (2008). The trans-species concept of self and the subcorticalcortical midline system. Trends in Cognitive Sciences, 12, 259-264.

Nuttall, J. (Ed.) (2013). Weaving Te Whāriki: Aotearoa New Zealand's Early Childhood Curriculum Document in Theory and Practice, $2^{\text {nd }}$ Edition. Wellington: NZCER Press New Zealand Council for Educational Research.

Packard, A., \& Delafield-Butt, J. T. (2014). Feelings as agents of selection: putting Charles Darwin back into (extended neo-) Darwinism. Biological Journal of the Linnean Society, 112, 332-353.

Panksepp, J. and Biven, L. (2012). Archaeology of Mind: Neuroevolutionary Origins of Human Emotions. New York: Norton.

Panksepp, J. (2005). Affective consciousness: Core emotional feelings in animals and humans. Consciousness and Cognition, 14, 30-80. 
Panksepp, J., \& Northoff, G. (2009). The trans-species core SELF: The emergence of active cultural and neuro-ecological agents through self-related processing within subcorticalcortical midline networks. Consciousness and Cognition, 18, 193-215.

Pezzulo,G., and Castelfranchi, C. (2009). Thinking as the control of imagination: a conceptual framework for goal-directed systems. Psychol. Res. 73, 559-577. doi: 10.1007/s00426009-0237-z

Piaget, J. (1953). The Origins of Intelligence in Children._London: Routledge and Kegan Paul.

Piaget, J. (1962). Play, Dreams and Imitation in Childhood. London: Routledge and Kegan Paul.

Porges, S. W., and Furman, S. A. (2011). The early development of the autonomic nervous system provides a neural platform for social behaviour: A polyvagal perspective. Infant and Child Development, 20, 106-118.

Quick, R. H. (1894). Essays on Educational Reformers. London : Longmans, Green and Co.

Read, S. J., and Miller, L. C. (1995). Stories are fundamental to meaning and memory: For social creatures, could it be otherwise? In Wyer, R. S. (ed.), Knowledge and Memory: The Real Story. Advances in Social Cognition. Hillsdale, NJ: Lawrence Erlbaum Associates, 139-152.

Reddy, V. (2003) On being the object of attention: implications for self-other consciousness. TRENDS in Cognitive Sciences, 7(9): 397-402

Reddy, V. (2005). Feeling shy and showing off: self-conscious emotions must regulate self awareness.. In J. Nadel, and D. Muir (Eds.), Emotional Development. (pp. 183-204). Oxford: Oxford University Press.

Reddy, V. (2008). How Infants Know Minds. Cambridge MA: Harvard University Press.

Reddy, V. (2015). Joining intentions in infancy. Journal of Consciousness Studies, 22(1-2), 2444.

Reddy, V. and Trevarthen, C. (2004) What we learn about babies from engaging with their emotions. Zero to Three, January 2004, Volume 24, No. 3, 9-15.

Reddy, V., Hay, D., Murray, L. and Trevarthen, C. (1997). Communication in infancy: Mutual regulation of affect and attention. In G. Bremner, A. Slater and G. Butterworth (eds.), Infant Development: Recent Advances, (pp. 247-274). Hove, East Sussex: Psychology Press.

Rogoff, B. (2003). The Cultural Nature of Human Development. Oxford: OUP.

Scaife, M. and Bruner, J. S. (1975) The capacity for joint visual attention in the infant. Nature 253: 265-6.

Sherrington, C. S. (1955). Man On His Nature. Harmondsworth: Penguin Books Ltd. The Gifford Lectures, 1937-1938.

Stern, D. N. (1971). A micro-analysis of mother-infant interaction: Behaviors regulating social contact between a mother and her three-and-a-half-month-old twins. Journal of American Academy of Child Psychiatry, 10, 501-517.

Stern, D. N. (1995). The Motherhood Constellation. New York: Basic Books.

Stern, D. N. (2000) The Interpersonal World Of the Infant: A View From Psychoanalysis and Development Psychology. (2nd edn., with new Introduction) New York: Basic Books.

Stern, D. N. (2004). The Present Moment: In Psychotherapy and Everyday Life. New York: Norton. 
Stern, D. N. (2010) Forms of Vitality: Exploring Dynamic Experience In Psychology, the Arts, Psychotheraphy and Development. Oxford: Oxford University Press.

Te Whàriki / He Whàriki Màtauranga mò ngà Mokopuna o Aotearoa. Early Childhood Curriculum (1996) For Ministry of Education, New Zealand Government. Wellington: Learning Media.

Thelin, N. (2014) On the Nature of Time: A Biopragmatic Perspective on Language, Thought and Reality. Uppsala University.

Tomasello, M. (2008). Origins of Human Communication. Cambridge MA:MIT Press

Trevarthen, C. (1974). The psychobiology of speech development. In E.H. Lenneberg (ed), Language and Brain: Developmental Aspects. Neurosciences Research Program Bulletin, 12: $570-585$.

Trevarthen, C. (1975). Early attempts at speech. In R. Lewin, Ed. Child Alive: New Insights Into the Development of Young Children. (pp. 62-80) London: Temple Smith.

Trevarthen, C. (1977). Descriptive analyses of infant communication behavior. In: H. R. Schaffer (Ed.) Studies in Mother-Infant Interaction: The Loch Lomond Symposium. London, Academic Press, pp 227-270

Trevarthen, C. (1979). Communication and cooperation in early infancy. A description of primary intersubjectivity. In M. Bullowa (Ed.) Before Speech: The Beginning of Human Communication. London, Cambridge University Press, , 321-347.

Trevarthen, C. (1984). How control of movements develops. In, H.T.A. Whiting (Ed.) Human Motor Actions: Bernstein Reassessed. Amsterdam: Elsevier (North Holland) 223-261.

Trevarthen, C. (1986). Form, significance, and psychological potential of hand gestures in infants. In Nespoulous, J. L., Perron, P., and Lecours, A. R. (eds.), The Biological Foundation of Gestures: Motor and Semiotic Aspects. Hillsdale, NJ: Erlbaum, 149-202.

Trevarthen, C. (1988). Universal cooperative motives: How infants begin to know language and skills of culture. In G. Jahoda and I.M. Lewis (Eds.), Acquiring Culture: Ethnographic Perspectives on Cognitive Development, (pp. 37-90). London: Croom Helm.

Trevarthen, C. (1992). An infant's motives for speaking and thinking in the culture. In: A. H. Wold (Ed), The Dialogical Alternative: Towards a Theory of Language and Mind (Festschrift for Ragnar Rommetveit). (pp. 99-137). Oslo/Oxford: Scandanavian University Press/Oxford University Press,.

Trevarthen, C. (1999). Musicality and the Intrinsic Motive Pulse: Evidence from human psychobiology and infant communication. Musicae Scientiae, Special Issue Rhythms, Musical Narrative, and the Origins of Human Communication, 157-213.

Trevarthen, C. (2001). Intrinsic motives for companionship in understanding: Their origin, development and significance for infant mental health. Infant Mental Health Journal, 22 (1-2) 95-131

Trevarthen, C. (2005). Stepping away from the mirror: Pride and shame in adventures of companionship Reflections on the nature and emotional needs of infant intersubjectivity. In, C.S. Carter, L. Ahnert, K. E. Grossman, S. B. Hrdy, M. E. Lamb, S. W. Porges and N. Sachser, eds. Attachment and Bonding: A New Synthesis. Dahlem Workshop Report 92. Cambridge, MA: The MIT Press. pp. 55-84

Trevarthen, C. (2012). Finding a place with meaning in a busy human world: how does the story begin, and who helps? European Early Childhood Education Research Journal, 20(3): 303-312. 
Trevarthen, C. (2015). From the Intrinsic Motive Pulse of infant actions, to the life time of cultural meanings. In, B. Mölder, V. Arstila, P. Ohrstrom (Eds.) Philosophy and

Psychology of Time For Springer "Studies in Brain and Mind" series ( http://www.springer.com/series/6540). Vienna/New York: Springer. (in press).

Trevarthen, C. and Aitken, K.J. (2003). Regulation of brain development and age-related changes in infants' motives: The developmental function of 'regressive' periods, in M. Heimann (ed.), Regression Periods in Human Infancy. Mahwah, NJ: Erlbaum. pp.107184.

Trevarthen, C. and Bjørkvold, J.-R. (2016, in press). Life for learning: How a young child seeks joy with companions in a meaningful world. In D. Narvaez, J. Braungart-Rieker, L. Miller, L. Gettler, and P. Hastings (Eds.), Contexts for Young Child Flourishing: Evolution, Family and Society. Chapter 2. New York, NY: Oxford University Press.

Trevarthen, C. and Delafield-Butt, J. T. (2013). Biology of shared experience and language development: Regulations for the inter-subjective life of narratives. In, M. Legerstee, D. Haley and M. Bornstein (Eds.) The Infant Mind: Origins of the Social Brain. New York: Guildford Press, pp. 167-199.

Trevarthen, C. and Delafield-Butt, J. T. (2015). The infant's creative vitality, in projects of self-discovery and shared meaning: How they anticipate school, and make it fruitful. In S. Robson and S. F. Quinn (Eds.), International Handbook of Young Children's Thinking and Understanding (pp. 3-18). Abingdon, Oxfordshire and New York: Routledge.

Trevarthen, C. and Hubley, P. (1978) Secondary intersubjectivity: confidence, confiding and acts of meaning in the first year. In: Action, Gesture and Symbol: The Emergence of Language, Lock A, ed. London, New York, San Francisco: Academic Press, pp. 183-229.

Trevarthen, C. and Malloch, S. (2012). Musicality and Musical Culture: Sharing Narratives of Sound from Early Childhood. In, Oxford Handbook of Music Education (OHME) Ed. G. McPherson and G. Welch, 248-260. Oxford: Oxford University Press.

Trevarthen, C. and Malloch, S. (2016, in press). Grace in moving and joy in sharing: The intrinsic beauty of communicative musicality from birth. In, S. Bunn, Ed. Anthropology and Beauty: From Aesthetics to Creativity. Abingdon: Routledge

Trevarthen, C. and Reddy, V. (2016, in press). Consciousness in infants. In, S. Schneider and M. Velmans (Eds.). Blackwell Companion to Consciousness, Second Edition. Oxford: Blackwells

von Hofsten, C. (1989). Motor development as the development of systems: Comments on the Special Section. Developmental Psychology, 25(6), 950-953.

Vandekerckhove, M., \& Panksepp, J. (2011). A neurocognitive theory of higher mental emergence: From anoetic affective experiences to noetic knowledge and autonoetic awareness. Neuroscience \& Biobehavioral Reviews, 35 (9), 2017-2025.

Vygotsky, L.S. (1978). Mind in Society: The Development of Higher Psychological Processes. (Edited by M. Cole, V. Steiner, S. Scribner and E. Souberman). Cambridge, Mass: Harvard University Press.

White, E. J. and Mika, C. (2013). Coming of age? Infants and toddlers in the curriculum. In Nuttall, J. (Ed.) Weaving Te Whāriki: Aotearoa New Zealand's Early Childhood Curriculum Document in Theory and Practice (2nd ed.), pp. 93-113. Wellington: NZCER Press New Zealand Council for Educational Research. 